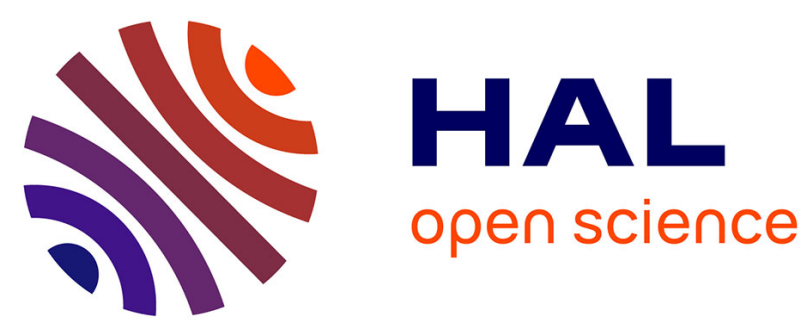

\title{
Development of a probe for in-situ radiative heat flux measurements at the surface of an ablator
}

\author{
Sean Mcguire, Gilles Bailet, Christophe O Laux
}

\section{To cite this version:}

Sean Mcguire, Gilles Bailet, Christophe O Laux. Development of a probe for in-situ radiative heat flux measurements at the surface of an ablator. 2018 AIAA Aerospace Sciences Meeting, Jan 2018, Kissimmee, United States. 10.2514/6.2018-0498 . hal-01866396

\section{HAL Id: hal-01866396 https://hal.science/hal-01866396}

Submitted on 27 Mar 2019

HAL is a multi-disciplinary open access archive for the deposit and dissemination of scientific research documents, whether they are published or not. The documents may come from teaching and research institutions in France or abroad, or from public or private research centers.
L'archive ouverte pluridisciplinaire HAL, est destinée au dépôt et à la diffusion de documents scientifiques de niveau recherche, publiés ou non, émanant des établissements d'enseignement et de recherche français ou étrangers, des laboratoires publics ou privés. 


\title{
Development of a probe for in-situ radiative heat flux measurements at the surface of an ablator
}

\author{
Sean D. McGuire, Gilles Bailet ${ }^{\dagger}$ and Christophe O. Laux ${ }^{\ddagger}$ \\ Laboratoire EM2C, CNRS UPR288, CentraleSupélec, Université Paris-Saclay \\ 10 rue Joliot-Curie, F-91190, Gif-sur-Yvette, France
}

\begin{abstract}
We present a radiative heat flux probe capable of directly accessing a radiative boundary layer around an ablative sample. Unlike previous approaches that have suffered from pollution of the optical system by ablative species, our probe utilizes a system for preventing contamination of the optical system. We are therefore able to make measurements over a long period of time during testing in a plasma torch facility. The probe operates on a battery-powered system and can therefore be installed in facilities without optical access. It is designed for use under a wide variety of conditions within ground test facilities. Prototype tests of the probe were performed in our $50 \mathrm{~kW}$ plasma torch facility to study an equilibrium air flow around an ablative CBCF turning wedge and flat surface samples. Further tests of the probe were performed in the much larger plasmatron facility at VKI to demonstrate probe functionality.
\end{abstract}

\section{Introduction}

Within the field of atmospheric reentry, a lot of work over the last decade has focused on studying gas surface interactions and the phenomenon of ablation which introduces additional chemical species into the boundary layer around an ablative sample. D'Souza et al [1] looked at the formation of ablative species in their expansion facility. Wernitz et al [2] used a plasma wind tunnel facility to model the atmosphere of Titan and looked at the formation of $N_{2}, N_{2}^{+}$and $C_{2}$ species within an ablative boundary layer. Additional work has looked at air and nitrogen flows, and the ablative species introduced within the boundary layer and post shock regions[3, 4, 5, 6, 7]. Much of this work has focused on both $\mathrm{C}$ and $\mathrm{CN}$ emission. The standard approach is to use optical emission spectroscopy (OES) in a cross flow configuration, where the optical emission system looks along a line-of-sight traversing the flow. The measurement is therefore line-of-sight integrated. If the flow is axisymmetric and the emission optically thin, then the emission spectra may be Abel inverted to provide the spatially resolved volumetric emission from the plasma.

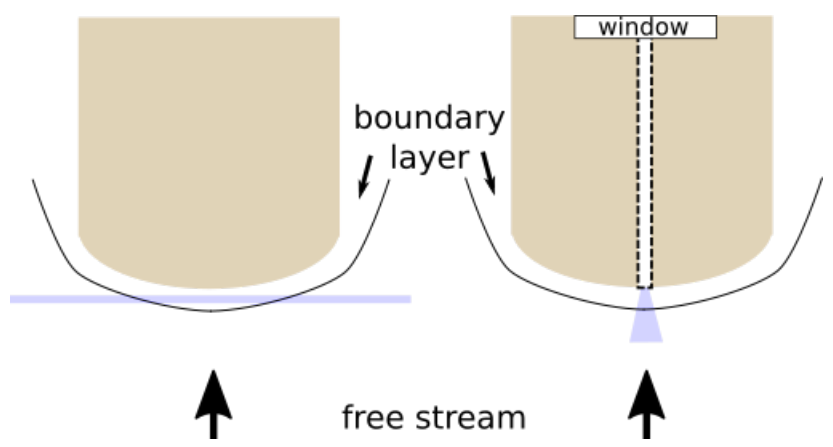

Figure 1: (Left): Cross-flow configuration with the line-of-sight highlighted in violet. (Right): Embedded optical pathway configuration permittings direct access to the boundary layer.

Some researchers have embedded optical pathways directly into test articles to make direct radiative heat flux measurements along the stagnation line $[3,5,8]$. These optical pathways then relay the stagnation line emission to a

\footnotetext{
*Assistant Professor, Laboratoire EM2C, CNRS UPR288, CentraleSupélec, Université Paris Saclay, AIAA Member

${ }^{\dagger}$ Graduate Student, CentraleSupélec

${ }^{\ddagger}$ Professor, Laboratoire EM2C, CNRS UPR288, CentraleSupélec, Université Paris Saclay, AIAA Associate Fellow
} 
spectrometer for analysis. Hermann et al[5] embedded an optical pathway into an ablative test article and made VUV measurements of the plasma. They compared stagnation line spectra between a CALCARB ablator test article and a non-ablative copper test article to isolate effects coming from ablation. An advantage of this second approach is that it provides direct measurements of the radiative heat flux directed to the surface. This is particularly useful for transitions in the deep UV and VUV regions of the spectra, where radiation can become optically thick. Within a high temperature ablative boundary layer, for example, ablative species such as CO can locally enhance absorption of UV and VUV radiation via the 4th positive transition. The approach of Palumbo et al [8] and Hermann et al [3,5] is well suited for measuring such phenomena because it permits direct access to the ablative boundary layer. However, for Hermann and Loehle et al, who used an ablative test article, pollution from ablative species prevented measurements much after the beginning of the test.

Our goal is to expand upon the work of Palumbo et al and Loehle and Hermann et al, and to develop a probe for directly measuring the radiative heat flux to the surface of an ablative test article under realistic reentry situations. For this, we developed a small miniaturized probe based around an STS Ocean Optics spectrometer. The probe is embedded within the TPS material. In addition to the spectrometer, the probe contains electrical control circuitry, a battery and a micro SD card to store data. The probe is thus autonomous and may be directly inserted into ground test facilities. This is particularly useful and, because the probe is small, it may be installed inside facilities that have limited optical access or suffer from other restrictions. Furthermore, the probe utilizes a recently patented technology for preventing pollution of the optical system by ablative species (REFERENCE).

In this paper, we measured the emission intensity directly at the surface of a CBCF ablator. For prototype testing, we used a $50 \mathrm{~kW}$ plasma torch facility to supply a high enthalpy plasma jet of air at $1 \mathrm{~atm}$ with a centerline temperature of about $7000 \mathrm{~K}$. We chose two standard configurations for our measurements: a turning wedge and a flat surface. These geometries permit a boundary layer to develop along the sample which is then accessed using our miniaturized probe. After prototype testing in the $50 \mathrm{~kW}$ plasma torch, the probe was successfully tested in the Von Karman Institute plasmatron facility where stagnation line spectra were obtained. The advantage of this approach is its robustness and relative simplicity. The probe is small with a length of approximately $10 \mathrm{~cm}$ and a diameter of $5 \mathrm{~cm}$. Given an appropriate adapter, the probe may be installed in any facility and used to provide a measurement of the radiative flux to the ablator surface.

\section{Experimental Setup}

\section{Spectroscopic Measurement Probe}

Figure 2 show two images of the spectroscopic probe. A small channel is drilled into the ablative test article to provide line-of-sight access to the boundary layer. A patented design is used to reduce contamination of the optical elements on the interior by ablative products: details of this design are in the patent which is forthcoming.(REFERENCE) A miniature Ocean Optics STS spectrometer is mounted on the interior of the probe and looks through the small channel drilled in the ablative test article. The spectrometer is controlled via an mbed microcontroller and a custombuilt electrical circuit: the diagram for this circuit is shown in Fig. 3. The entire system is powered via a Lithium Ion battery pack. A voltage adapter regulates the voltage input from the battery pack down to $5 \mathrm{~V}$ for powering the circuit. The mbed communicates with the spectrometer through a MAX232 which converts commands to and data from the STS to the appropriate format. In addition to taking spectra, the temperature is monitored using a thermistor on board the STS. All information is then stored on a micro SD card for later retrieval. The Ocean Optics STS spectrometer comes in three available options spanning the UV to the infrared. The spectrometers are completely interchangeable and thus there is a capability to operate from the UV to the near IR. After testing, all data are offloaded to a computer for analysis and post-processing. The measurements in this paper were made using an Ocean Optics STS-UV spectrometer. For emission measurements, the spectrometer was calibrated in relative intensity using a calibrated argon discharge traceable to NIST standards. It is possible to calibrate the probe in absolute intensity, but for these initial prototype tests, a relative calibration was sufficient. Stray light can be an important consideration, particularly at ultraviolet wavelengths approaching $200 \mathrm{~nm}$ where the spectrometer sensitivity becomes an issue. To account for stray light, the measured intensity value at $185 \mathrm{~nm}$ (the lower limit of the spectrometer spectral window) was subtracted from the spectral intensity. At $185 \mathrm{~nm}$, the signal should be zero due to absorption from $\mathrm{O}_{2}$ in the optical path and thus this value represents a measurement of the stray light magnitude. If this correction was not performed, strong deviations in signal intensity would be observed below about $240 \mathrm{~nm}$.

To protect the control circuitry and hardware, the probe is surrounded by a cylindrical cork sleeve made of Amorim P50 cork. The final diameter of the probe depends upon the sleeve thickness chosen. The diameter of the bare probe 

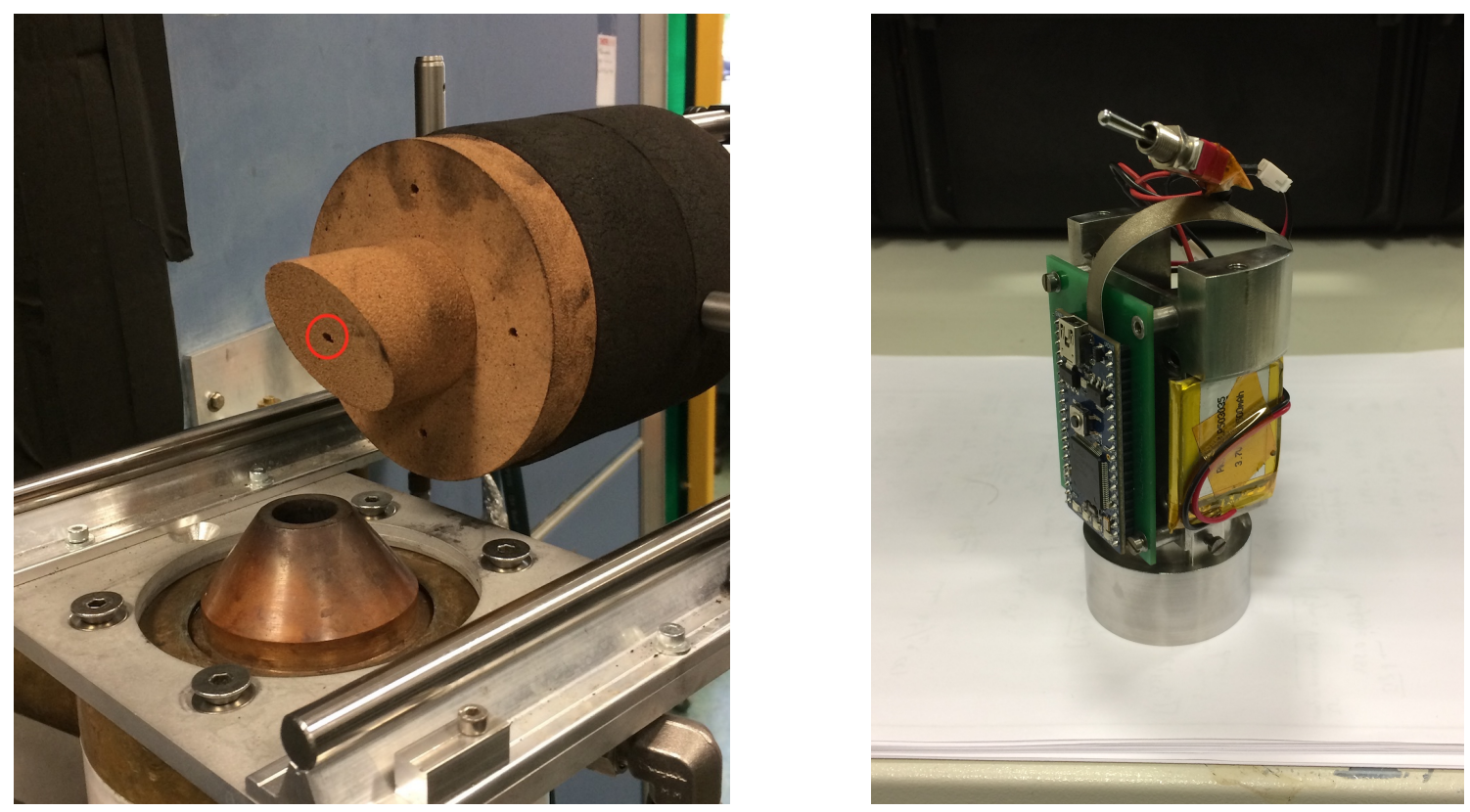

Figure 2: (Left) Spectroscopic probe mounted above the 2-cm exit nozzle of the $50 \mathrm{~kW}$ plasma torch facility. The red circle indicates the opening through which the spectrometer on the interior of the probe looks through. The wedge mounted on the front represents the test article. In this image, the test article is made out of P50 cork manufactured by Amorim. The design is modular and this test article may easily be replaced in between tests. It may be manufactured to various geometries in order to replicate certain conditions. The cylindrical portion of the probe behind the test article houses the spectrometer, electrical control circuitry and battery pack. These items are protected by a cylindrical sleeve of P50 cork material, which is black due to previous use. (Right) Interior of SPP probe showing mbed microcontroller, lithium ion battery pack and control circuitry. A miniature Ocean Optics SPP spectrometer is mounted on the reverse face.
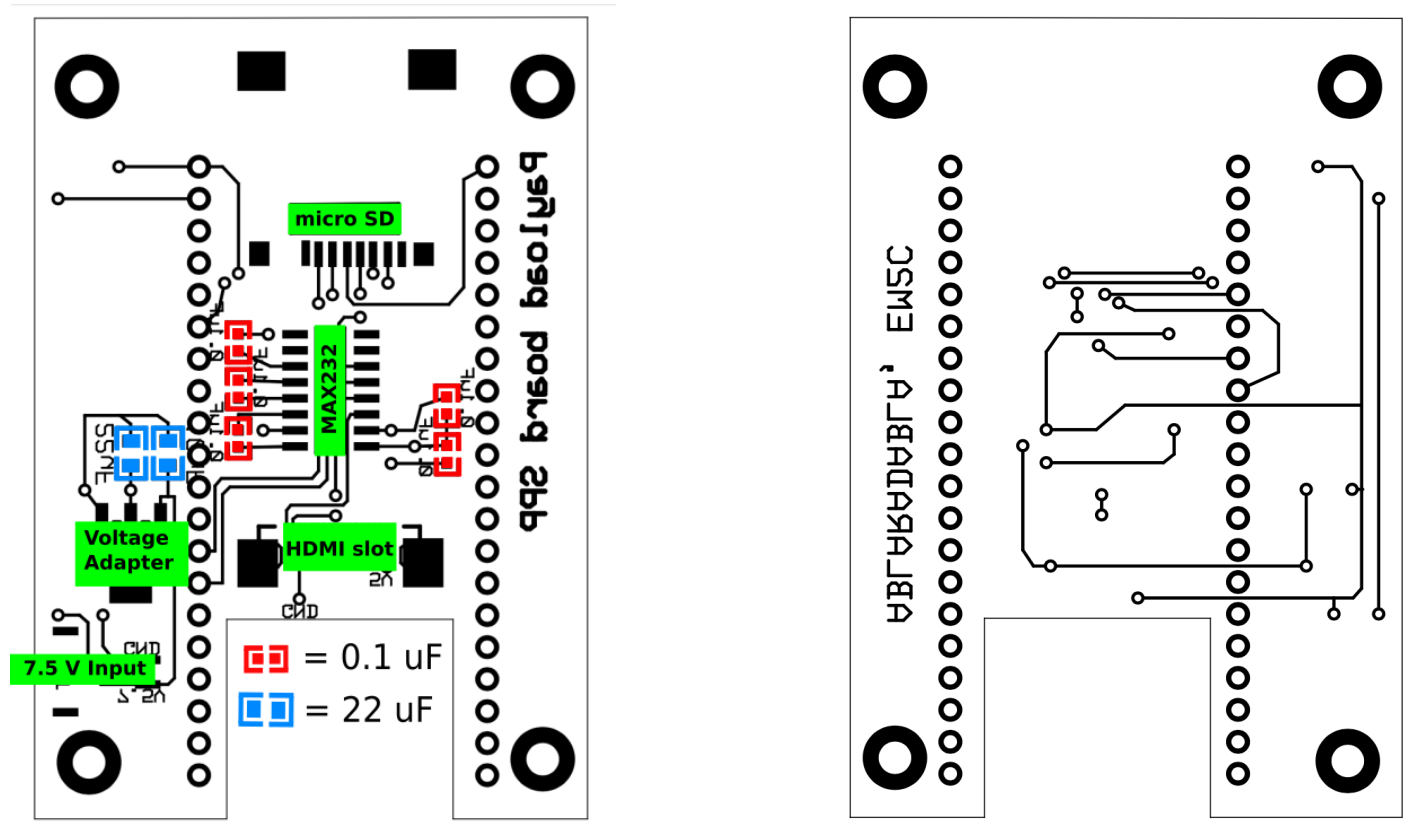

Figure 3: (Left): Front face image of printed circuit board used to control the SPP spectrometer. (Right): Reverse face image. The mbed microcontroller is mounted directly to this face. 
with no sleeve is about $6.5 \mathrm{~cm}$. We typically use a cylindrical sleeve with a wall thickness of about $2.25 \mathrm{~cm}$, giving the probe a diameter of $11 \mathrm{~cm}$. Our tests, which were conducted under relatively extreme conditions, indicate that a much thinner sleeve would suffice. This is especially true for lower heat flux applications. The test article is then mounted to this sleeve using holding pins and, when necessary, temperature-resistant silicon adhesive is used for additional support. For testing, the circuit is first powered on; the final components of the protective cork sleeve are put in place; the probe is mounted inside the test facility; the test is run; and finally the probe is retrieved and the data extracted.

\section{2. line-of-sight measurement}

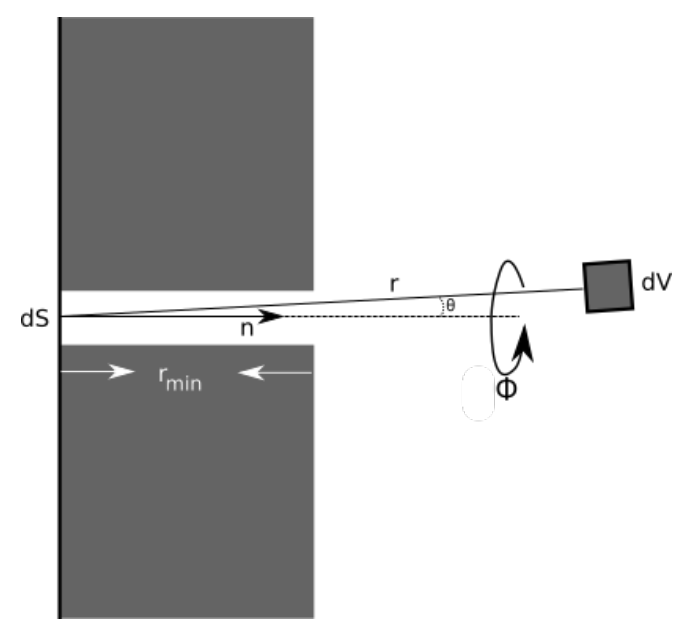

Figure 4: Geometry for the line-of-sight and view factor calculation. $n$ represents the surface normal of the spectrometer entrance and $r_{\min }$ the length of the canal drilled into the ablative sample to permit viewing access.

Consider the power emitted from a portion of the radiating flow of volume $d V$ and what fraction of energy reaches the spectrometer inside the probe: i.e. what is the view factor between the differential volume and the spectrometer entrance of area $\delta S$. Figure 4 illustrates the geometry of the problem. Note that the spectrometer entrance slit has a width of $10 \mu \mathrm{m}$ and is therefore much smaller than the canal diameter of $5 \mathrm{~mm}$. The canal drilled into the ablative material has a certain length $r_{0}$. If $\mathcal{I}$ represents the volumetric emission in $W / \mathrm{m}^{3} / \mathrm{sr} / \mathrm{nm}$ from a point in the radiating flow and the flow is optically thin, then the power incident upon the spectrometer coming from this differential element is:

$$
d^{4} \Phi_{i}=\mathcal{I} \delta S\left(\frac{\hat{n} \cdot \hat{r}}{r^{2}}\right) d V d \lambda
$$

where the superscript 4 on $d^{4} \Phi_{i}$ denotes that the derivative is taken with respect to four variables: $d V$ counting as three and $d \lambda$. Assuming a isotropic and uniform integrated intensity $\mathcal{L}=\int \mathcal{I} d \lambda$, this equation may be integrated using a spherical coordinate system centered on the spectrometer entrance slit to yield the total power incident upon the slit:

$$
\Phi_{i}(r)=\int_{r_{m i n}}^{r} v(r, \theta) \mathcal{L}(r, \theta, \phi) 4 \pi r^{2} \sin \theta d r d \theta d \phi
$$

where

$$
v(r, \theta)=\frac{\cos \theta}{4 \pi} \frac{\delta S}{r^{2}}
$$

represents the view factor between the differential element and the spectrometer. Given the spectrometer entrance slit diameter of $10 \mu \mathrm{m}$ and a canal length of $20 \mathrm{~mm}$, Fig. 5 shows the value of the view factor in the domain surrounding the canal exit.

If we assume that $\mathcal{L}$ is only a function of $r$ then we can look at several cases regarding this dependence. Figure 5 shows the integrated line-of-sight of site $\Phi_{i}(r)$ for various dependencies of $\mathcal{L}$. Note that, we are interested in using this probe to look at boundary layer effects. However, as Fig. 5 shows, the probe is sensitive to light coming from outside the boundary layer as well: even though the view factor drops rapidly with distance as $1 / r^{2}$, the surface which comes 

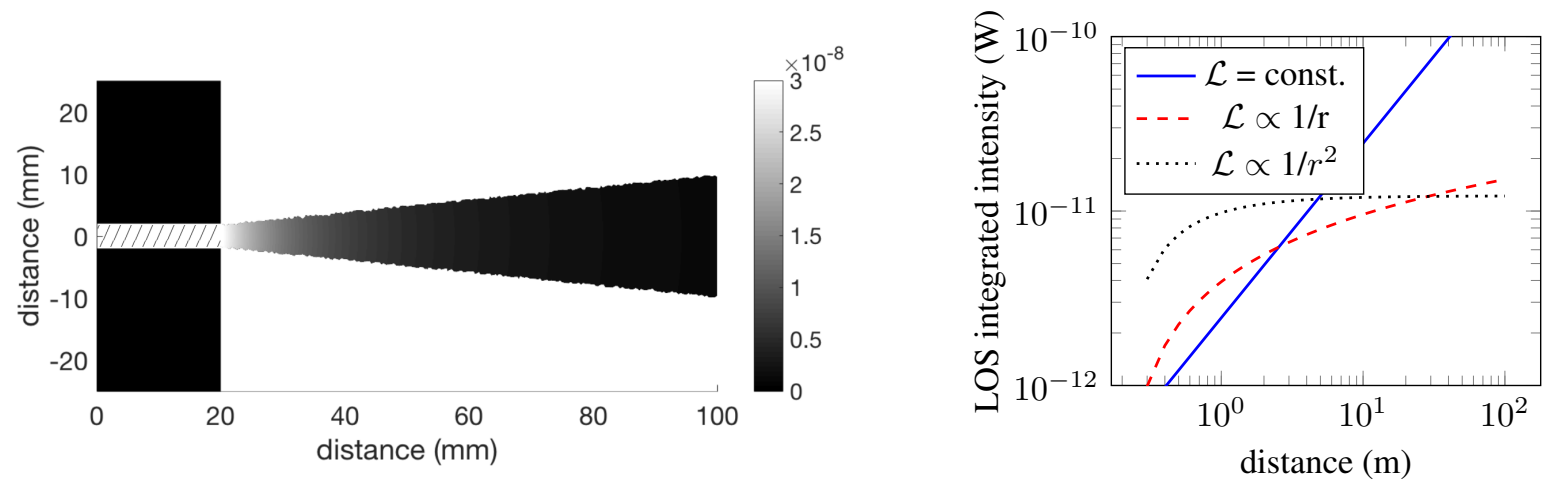

Figure 5: (Left): View factor calculation for a spectrometer entrance slit diameter of $10 \mu \mathrm{m}$ and a canal length and width of $20 \mathrm{~mm}$ and $4 \mathrm{~mm}$, respectively. (Right): Integrated line-of-sight calculation for various dependencies of $\mathcal{L}$ on radial distance $r: \mathcal{L}=$ const, $\mathcal{L} \propto 1 / r$ and $\mathcal{L} \propto 1 / r^{2}$. Note that, in every case except the last one, $\Phi(r) \rightarrow \infty$ diverges.

into the field of view of the spectrometer grows as $r^{2}$. This is a particular problem when dealing with a plasma torch facility, where there is a hot reservoir whose emission simply overshadows the boundary layer emission. To get around this problem, Loehle et al used an angled line-of-sight.[3] In our experiments, to avoid line-of-sight interference from the plasma torch reservoir, the line-of-sight was oriented as in Figures 2 and 7.

\section{Plasma Torch Facility}

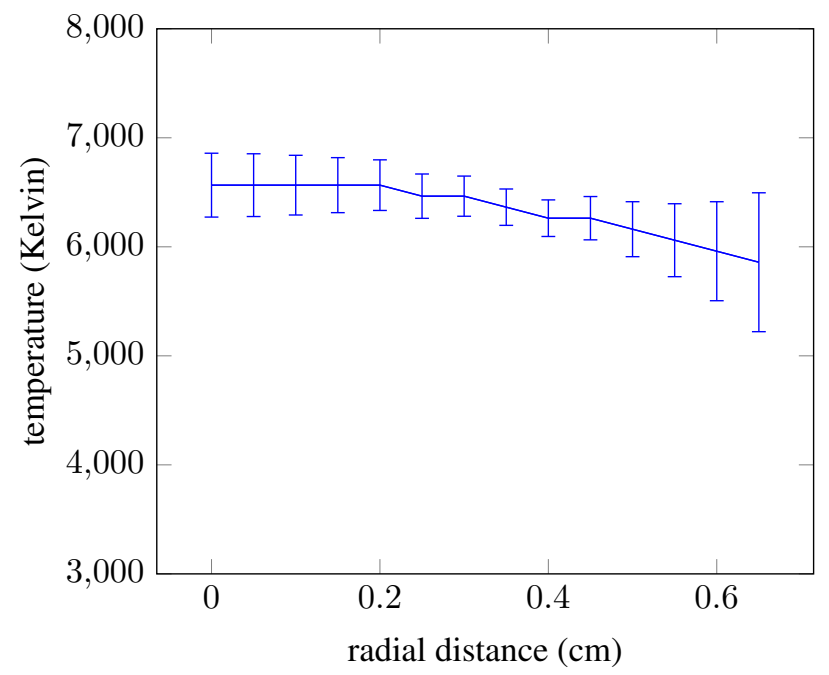

Figure 6: Temperature profile, measured via atomic oxygen emission at $777 \mathrm{~nm}$, at the exit of the $2 \mathrm{~cm}$ nozzle of the plasma torch facility. The plasma has been verified to be at local thermodynamic equilibrium (Ref. [9]).

The plasma torch facility used is a TAFA Model 66 inductively coupled plasma (ICP) torch powered by a 120 kVA radio frequency LEPEL Model T-50-3 power supply. The power supply operates at $4 \mathrm{MHz}$ and can supply a maximum of $12 \mathrm{kV}$ DC and $7.5 \mathrm{~A}$ to the oscillator plates. Details of the plasma torch facility are provided in previous publications.[6, 10,11] For these experiments, a $2 \mathrm{~cm}$ diameter exit nozzle was used and the facility was operated with air. The centerline temperature and velocity are approximately $6500 \mathrm{~K}$ and $140 \mathrm{~m} \mathrm{~s}^{-1}$.[10] The temperature is measured from the absolute emission intensity of atomic oxygen at $777 \mathrm{~nm}$. 


\section{Results}

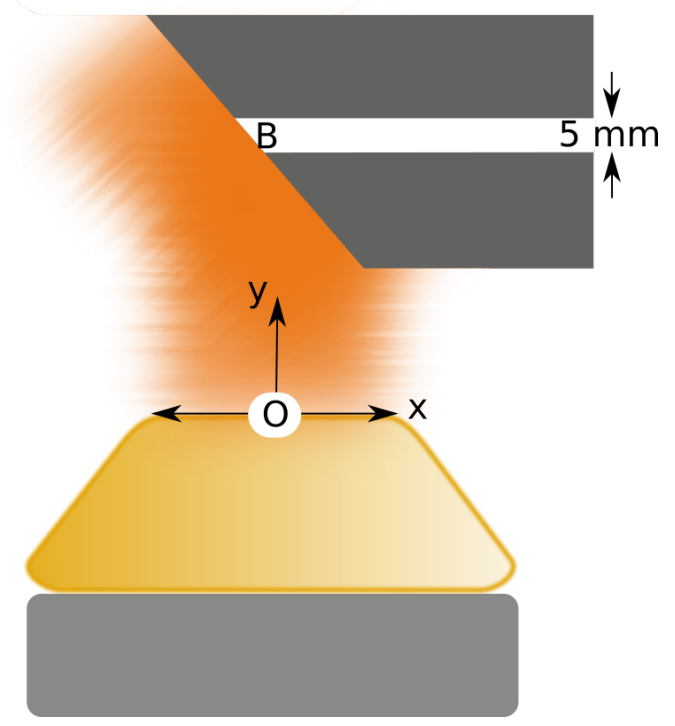

Figure 7: Wedge configuration used in torch facility for radiation measurements. The exit nozzle diameter of the torch is $2 \mathrm{~cm}$. The wedge angle is $45^{\circ}$. $O$ represents the origin of a coordinate system. The coordinates of $B$ are $(\mathrm{x}, \mathrm{y})=$ $(0.2,3.5) \mathrm{cm}$.

The turning wedge in Fig. 7 was manufactured out of $\mathrm{CBCF}$ material and a 5-mm diameter canal was drilled into the sample. Figure 8 shows the results from the experiment. Because the probe is calibrated in relative intensity and not absolute, the relative structure of the spectra must be used for a temperature estimate. As seen in the figure, the agreement with emission from $6000 \mathrm{~K}$ equilibrium air calculated with specair [12] is quite good. Emission below 300 $\mathrm{nm}$ comes primarily from NO, while between $300 \mathrm{~nm}$ and $400 \mathrm{~nm}$, the emission comes primarily from $N_{2}$ second positive and $\mathrm{CN}$ violet bands. No ablative species were observed in the emission spectrum: e.g. $\mathrm{CO}$ 4th positive emission or additional $\mathrm{CN}$ violet emission beyond what is expected from equilibrium air. Furthermore, there was no indication that the emission was attenuated due to absorption from ablative products within the boundary layer.

No pollution of the interior optical system was observed over the 1 minute duration of the test thus showing there was no significant coating of the optical components. As seen in the time-history of the intensity, there are several moments, when the intensity abruptly increases during the beginning portion of the test. This is likely due ??????

For comparison with the wedge configuration measurements, we also performed measurements using a flat surface (Fig. 9). The observed emission temperature was approximately $6000 \mathrm{~K}$. As with the wedge, there was no discernible effect from ablative species in the boundary layer: no observable emission from these species nor absorption by these ablative species of the signal emitted by the free stream. In order to amplify the impact of ablative species on the spectra, an inverted wedge (or backward facing step) configuration was also tried. It was expected that this would reduce emission from the hot free stream to the spectrometer and, through the generation of a recirculation region near the wall, trap ablative species close to the observation point. However, here again, no effect from ablative species was observed on the emission signal.

\section{Discussion}

We have previously used infrared absorption and emission spectroscopy to study the formation of carbon monoxide in a high temperature boundary layer.[13] These measurements were done while looking at a high enthalpy flow over a bluff body: the sample was cylindrical and was oriented such that the circular face corresponded to the stagnation point. Downstream measurements along the sample surface looked at $\mathrm{CO}$ production and found significant quantities of $\mathrm{CO}$ at temperatures around 4000 - $4500 \mathrm{~K}$ within the boundary layer. We built upon some of this work by adding an ultraviolet emission system to look at ultraviolet emission from CO 4th positive and atomic carbon.[14] However, we found that the $\mathrm{CO}$ 4th positive emission could not be definitively identified as it was overshadowed by NO emission 

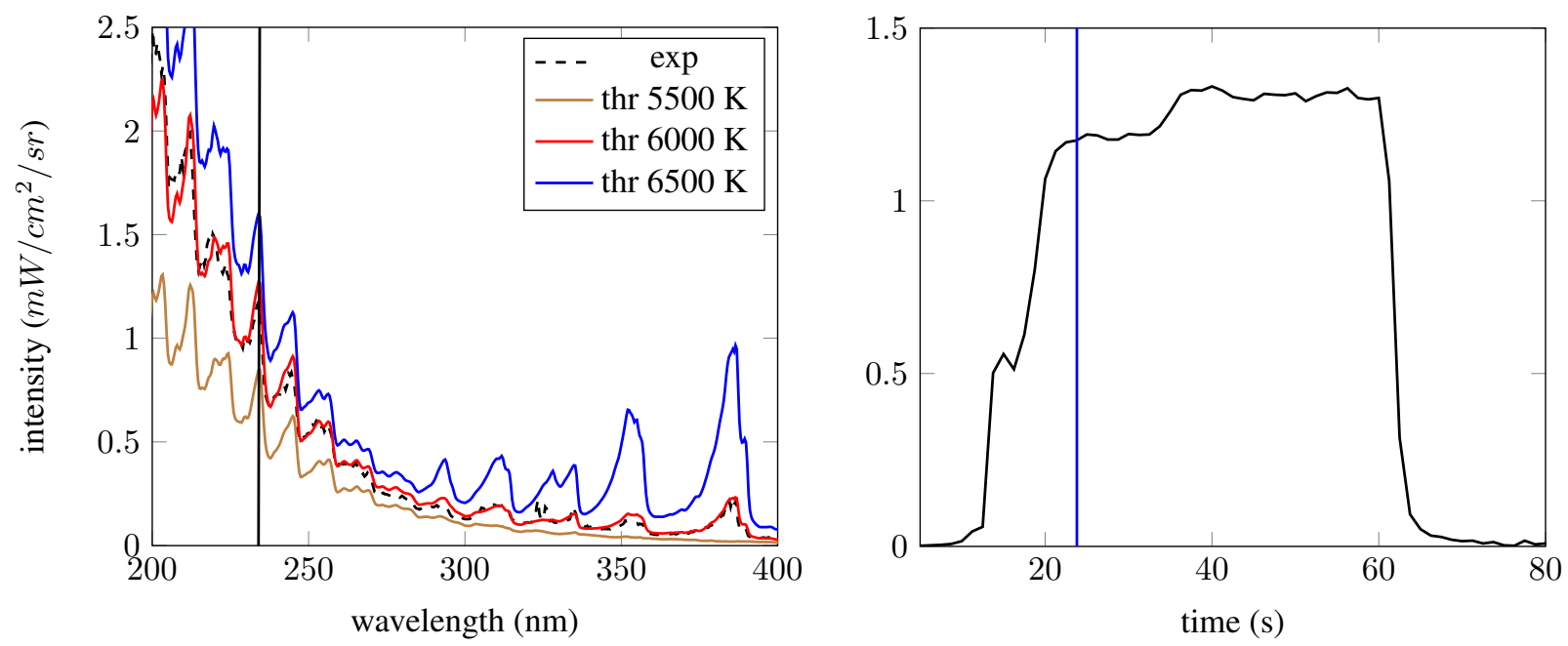

Figure 8: (Left): Spectra obtained approximately 10 seconds after probe insertion. The experimental emission was scaled to match the emission from a $1 \mathrm{~cm}$ slab of equilibrium air at $6000 \mathrm{~K}$ for wavelengths above $250 \mathrm{~nm}$. (Right) Time dependent intensity vs time. The intensity was measured at a wavelength of $235.5 \mathrm{~nm}$ (black line in A). The blue line denotes the point in time when the spectrum in A was reported. The drop in signal at the end corresponds to the time at which when the plasma torch was turned off.
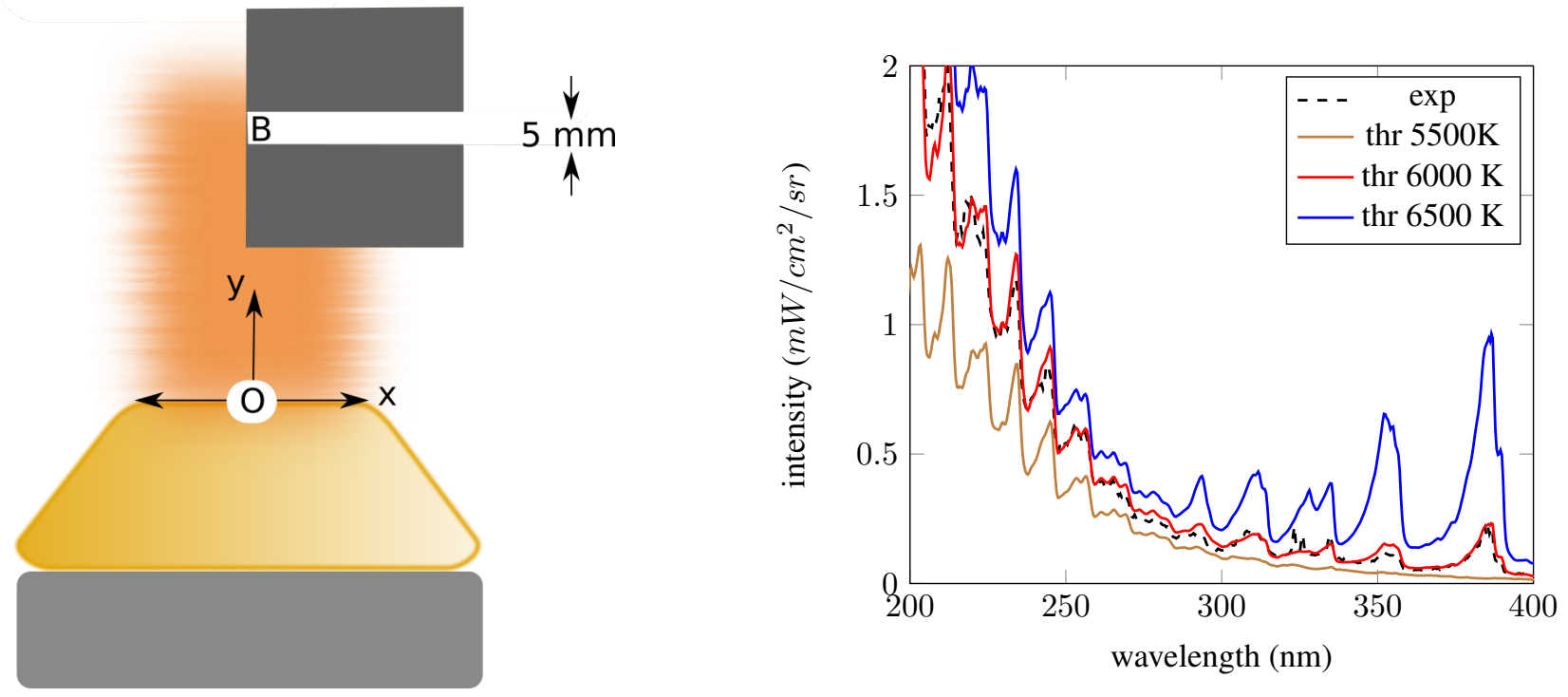

Figure 9: (Left): Flat plate configuration used for air measurements. $O$ represents the origin of the coordinate system. The coordinates of $B$ are $(\mathrm{x}, \mathrm{y})=(0,4) \mathrm{cm}$. (Right) Measured emission spectra (dashed/blue) as compared to equilibrium air emission at several temperatures. The experimental emission was scaled to match the emission from a 1-cm slab of equilibrium air at $6000 \mathrm{~K}$ and $1 \mathrm{~atm}$.

from equilibrium air. Atomic carbon emission was observed though it was not found to be much more intense than the equilibrium air emission. Those measurements were done under conditions different to those in this work: among other things, the temperature was lower. However, they do suggest that ultraviolet emission from $\mathrm{CO}$ 4th positive or atomic carbon are not the dominant radiators which is consistent with the observations in this paper.

To assess the probe functionality under more extreme conditions, we also tested the probe in the VKI plasmatron facility. The plasmatron is an inductively coupled torch facility that can reach high total power levels and typically 

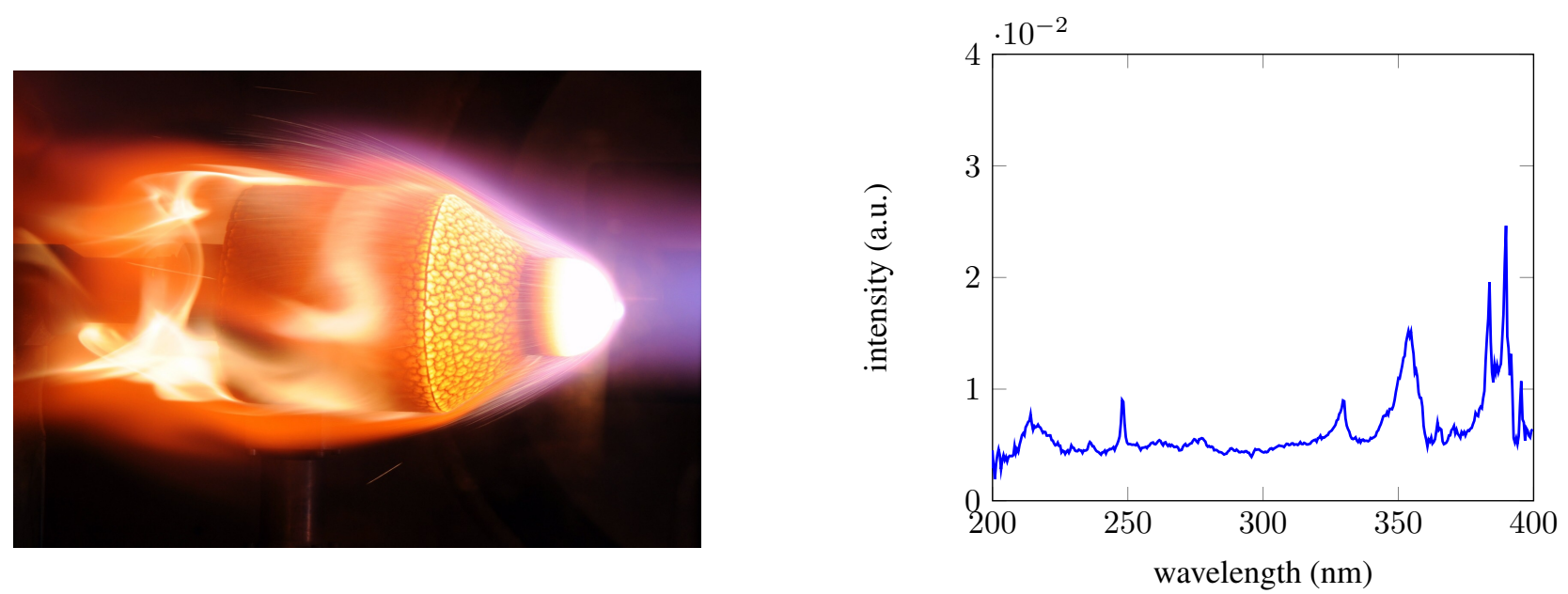

Figure 10: (Left): Image of the SPP probe being tested in the VKI plasmatron. (Right): Spectra taken with the SPP probe in the VKI plasmatron. The primary structure in the spectrum between 325 and $400 \mathrm{~nm}$ is $N_{2}^{+}$first negative emission. Also note the peak at $248 \mathrm{~nm}$ which corresponds to atomic carbon emission.

operates at sub-atmospheric pressure. For details of this facility, see References $[4,15,16,17]$. For these experiments, the plasmatron was used with air injection and a ZURAM 5-cm diameter hemispherical test sample (PRESSURE AND HEAT FLUX???). ZURAM is a lightweight carbon phenolic ablator jointly developed by the Helmholtz Association (HGT), the German Aerospace Centre and the University of Stuttgart[18]. Figure 10 shows an image of the probe being tested in the plasmatron. The probe was oriented to look at stagnation line emission. However, due to the line-of-sight considerations mentioned earlier, stagnation line emission was dominated by emission from the upstream plasma and RF coil region. Future work will look at mitigating this problem using angled line-of-sight measurements as in Loehle et al.[3] Nevertheless, these prototype tests demonstrated that the probe operates successfully under extreme enthalpy conditions.

\section{Conclusion}

In this paper, we present a radiative heat flux probe capable of making in-situ measurements of radiative heat flux to a sample surface. The approach builds upon previous work focused on directly accessing a radiating boundary layer. The probe does not suffer from pollution of the optical components by ablative products, therefore permitting stable measurements of radiative heat flux to a sample surface. The probe is autonomous and small scale. Its operation has been validated in the EM2C laboratory plasma torch facility and VKI plasmatron facility over a wide range of operating conditions. The probe is particularly well suited for isolating local absorption/emission from ablative species introduced within the boundary layer about the test sample. The tests conducted here successfully demonstrated an operational probe. Evidence of local absorption or emission from ablative species in the boundary layer was not found in the measured spectra for the conditions examined. We have previously identified $\mathrm{CO}$ in an ablative boundary layer around a cylindrical sample, downstream of the stagnation point.[13, 14] A next step may be to try and reproduce similar conditions around the SPP probe. In this previous work however, while infrared emission from CO was easily identified, $\mathrm{CO} 4$ th positive was not definitively identified due to strong NO ultraviolet emission. Beyond looking for evidence of $\mathrm{CO}$ 4th positive emission, side looking emission spectroscopy may also be used to identify flow composition at various distances from the sample surface in order to identify any spatial variation in emission from the flow around the sample. Future work will explore different experimental configurations in order to try and isolate these effects which have been predicted to have an impact on, for example, afterbody radiative heating.[19, 20] However, Johnston notes that, while ablation products had a significant impact on radiative heat flux to the vehicle surface, this was not due to local emission from these products in the boundary layer. Rather, the products have an effect on gas temperature which, in turn, reduces absorption of free stream emission within the boundary layer. Therefore, future experiments, rather than looking for direct evidence of ablative species emission/absorption perhaps should be designed to identify a broader set of possible effects due to the presence of ablative species within the boundary layer, including an effect on gas temperature. 


\section{Acknowledgments}

This work was funded in part through ESA grant ESA ITT AO/1-7987/14/NL/RA (Ablation and Radiation in the Presence of Light Ablators) supervised by Lionel Marraffa. We would like to thank VKI for the use of their plasmatron and for collaborating with us on this work: in particular Bernd Helber, Alessandro Turchi, Thierry Magin and .... ????

\section{References}

1 Mary G D'Souza, Troy N Eichmann, Daniel F Potter, Richard G Morgan, Timothy J McIntyre, Peter A Jacobs, and Neil R Mudford. Observation of an ablating surface in expansion tunnel flow. AIAA Journal, 48(7):1557-1560, 2010 .

${ }^{2}$ Ricarda Wernitz, Christoph Eichhorn, Thomas Marynowski, and Georg Herdrich. Plasma wind tunnel investigation for european ablators in nitrogen/methane using emission spectroscopy. International Journal of Spectroscopy, 2013(764321), 2013.

${ }^{3}$ S. Loehle, T. Hermann, F. Zander, H. Fulge, and T. Marynowski. Ablation Radiation Coupling Investigation in Earth Re-entry Using Plasma Wind Tunnel Experiments. 11th AIAA/ASME Joint Thermophysics and Heat Transfer Conference, Atlanta (USA), (AIAA 2014-2250):1-14, 2014.

4 Bernd Helber, Olivier Chazot, Annick Hubin, and Thierry E Magin. Microstructure and gas-surface interaction studies of a low-density carbon-bonded carbon fiber composite in atmospheric entry plasmas. Composites Part A: Applied Science and Manufacturing, 72:96-107, 2015.

5 Tobias Hermann, Stefan Loehle, Pénélope Leyland, Lionel Marraffa, Jean-Marc Bouilly, and Stefanos Fasoulas. First Results on Ablation Radiation Coupling Through Optical Emission Spectroscopy from the Vacuum Ultraviolet to the Visible. In European Symposium on Aerothermodynamics for Space Vehicles, 2015.

${ }^{6}$ M E MacDonald, C M Jacobs, C O Laux, F Zander, and R G Morgan. Measurements of Air Plasma/Ablator Interactions in an Inductively Coupled Plasma Torch. Journal of Thermophysics and Heat Transfer, 29(1):12-23, 2014.

7 Michael Winter, Bradley Butler, Paul M Danehy, Scott Splinter, Zhaojin Diao, Francesco Panerai, Alexandre Martin, and Sean Bailey. Characterization of Ablation Product Radiation Signatures of PICA and FiberForm. American Institute of Aeronautics and Astronautics, 2016.

8 Giuseppe Palumbo, Roger A Craig, Ellis W Whiting, and Chul Park. Measured specific intensity from 130 to 900 $\mathrm{nm}$ at the stagnation point of a model in an arcjet flow of $7.8 \mathrm{~km} / \mathrm{sec}$. Journal of Quantitative Spectroscopy and Radiative Transfer, 57(2):207-236, 1997.

${ }^{9}$ C O Laux. Optical Diagnostics and Radiative Emission of Air Plasmas. PhD thesis, Stanford University, Dept. of Mechanical Engineering, 1993.

10 M MacDonald and C O Laux. Experimental Characterization of Ablation Species in an Air Plasma Ablating Boundary Layer. In 11th AIAA/ASME Joint Thermophysics and Heat Transfer Conference, number AIAA-20142251. American Institute of Aeronautics and Astronautics, jun 2014.

11 M E MacDonald, C M Jacobs, and C O Laux. Interaction of Air Plasma With Ablating Heat Shield Material. IEEE Transactions on Plasma Science, 42(10):2658-2659, oct 2014.

12 C O Laux, T G Spence, C H Kruger, and R N Zare. Optical diagnostics of atmospheric pressure air plasmas. Plasma Sources Science and Technology, 12(2):125, 2003.

13 S D McGuire, A C Tibère-Inglesse, and C O Laux. Infrared spectroscopic measurements of carbon monoxide within a high temperature ablative boundary layer. Journal of Physics D: Applied Physics, 49(48):485502, 2016.

14 Sean McGuire and Christophe O. Laux. Experimental analysis of atomic carbon and carbon monoxide production within a high temperature ablative boundary layer. In 55th AIAA Aerospace Sciences Meeting. American Institute of Aeronautics and Astronautics, 2017. 
15 Bernd Helber, Alessandro Turchi, James B Scoggins, Annick Hubin, and Thierry E Magin. Experimental investigation of ablation and pyrolysis processes of carbon-phenolic ablators in atmospheric entry plasmas. International Journal of Heat and Mass Transfer, 100:810-824, 2016.

16 Alessandro Turchi, Pietro M Congedo, Bernd Helber, and Thierry E Magin. Thermochemical ablation modeling forward uncertainty analysis d Part II : Application to plasma wind-tunnel testing. International Journal of Thermal Sciences, 118:510-517, 2017.

17 Bottin B, Chazot O, Carbonaro M, Van Der Haegen V, and Paris S. The vki plasmatron characteristics and performance. In RTO AVT course on measurement techniques for high enthalpy and plasma flows RTO-EN-8, RhodeSaint-Genese, Belgium: von Karman Institue for Fluid Dynamics, 1999.

18 Adam Sean Patan, Christian Zuber, Bartomeu Massuti-Ballester, Georg Herdrich, Hermann Hald, and Stefanos Fasoulas. The ablation performance and dynamics of the heat shield material ZURAM. In 31st International Symposium on Space Technology and Science, 2017.

19 Christopher O Johnston, Peter A Gnoffo, and Alireza Mazaheri. Influence of Coupled Radiation and Ablation on the Aerothermodynamic Environment of Planetary Entry Vehicles. In Radiation and Gas-Surface Interaction Phenomena in High Speed Re-Entry, 2013.

20 C O Johnston and A M Brandis. Features of Afterbody Radiative Heating for Earth Entry. Journal of Spacecraft and Rockets, 52(1):105-119, 2014. 